\title{
The Composite Planning Technique in Left Sided Breast Cancer Radiotherapy: A Dosimetric Study
}

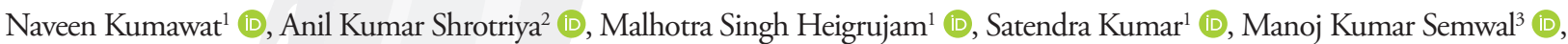 \\ Anil Kumar Bansal ${ }^{1}$ (D), Ram Kishan Munjal ${ }^{1}$ (D), Deepak Kumar Mittal ${ }^{1}$ (D), Charu Garg ${ }^{1}$ (D), Anil Kumar Anand ${ }^{1}$ (D) \\ ${ }^{1}$ Department of Radiation Oncology; Max Super Speciality Hospital, New Delhi, India \\ ${ }^{2}$ Department of Physics, SPSB Govt. PG College, Shahpura, India \\ ${ }^{3}$ Department of Radiotherapy, Radiotherapy Army Hospital (Research and Referral), New Delhi, India
}

\begin{abstract}
Objective: The aim of this retrospective study is to reduce the dose of heart, both lung and opposite breast and left anterior descending artery (LAD) and avoid long term complication and radiation induced secondary malignancies in radiotherapy left breast/chest wall without losing homogeneity and conformity of the Planning Target Volume (PTV), contoured using Radiotherapy Oncology Group (RTOG 1005) guideline.

Materials and Methods: The treatment plans were generated retrospectively by TFIF, VMAT and Composite techniques for 30 patients. DoseVolume Histograms (DVHs) were evaluated for PTV and organs at risk (OAR's) and analyzed in two groups BCS and MRM using Wilcoxon signed rank test.

Results: The homogeneity index (HI) was improved in Composite technique by $32.72 \%$ and $21.81 \%$ of VMAT, $50.66 \%$ and $49.41 \%$ of TFIF in BCS and MRM group respectively. The Conformity Index (CI) for composite plan was statistically same as VMAT and superior by $27.94 \%$ and $41.37 \%$ of TFIF in BCS and MRM group respectively. The low dose volume $\mathrm{V}_{5 \mathrm{~Gy}}$ and $\mathrm{V}_{10 \mathrm{~Gy}}$ of the heart were improved in Composite plan by $47.9 \%$ and $26.1 \%$ of VMAT respectively in BCS group and in MRM group, improved by $21.2 \%$ and $45.6 \%$ of VMAT. The $\mathrm{V}_{5 \mathrm{~Gy}}$ and $\mathrm{V}_{10 \mathrm{~Gy}}$ of ipsilateral lung were improved in Composite plan by 16\% and 13.7\% of VMAT respectively in BCS and 8.4\% and 3\% of VMAT respectively in MRM group.

Conclusion: The Composite plan consisting of VMAT and TFIF plan with an optimum selection of fractions can achieve lower low dose exposure to the OAR's without compromising coverage compared to VMAT.
\end{abstract}

Keywords: BCS, composite plan, breast, dosimetric comparison, MRM

Cite this articles as: Kumawat N, Shrotriya AK, Heigrujam MS, Kumar S, Semwal MK, Bansal AK, et al. The Composite Planning Technique in Left Sided Breast Cancer Radiotherapy: A Dosimetric Study. Eur J Breast Health 2020; 16(2): 137-145.

\section{Introduction}

Breast cancer or carcinoma of the breast (Ca-Breast) is the most common malignancy among women and the second most commonly occurring cancer overall in the world (1). In breast cancer, the most common treatment is conservative surgery or mastectomy followed by adjuvant chemotherapy and radiotherapy with or without hormonal therapy (2). Several prospective studies have shown that radiotherapy in Ca-Breast improved the disease free survival by almost $15 \%$ at 10 years and reduced the 15 -year risk of Ca-Breast death by $4 \%$ (3). Thus making the chronic sequelae of the breast cancer radiotherapy more important (4). But it has been shown that patients treated with radiation to chest wall or breast alone developed pneumonitis in 1\% cases which increased to $4 \%$ in patients treated with loco-regional irradiation including draining lymph node (5).

Oie et al. (6) reported that radiation pneumonitis (RP) mostly developed in ipsilateral lung and arose next to the rapidly decreasing dose area. Previous reports have shown that irradiation of the breast/chest wall with supraclavicular field led to an increased incidence of symptomatic radiation pneumonitis $(7,8)(\mathrm{SRP})$. Wen et al. (9) have suggested that the volume receiving 20Gy and 30Gy $\left(\mathrm{V}_{20 \mathrm{~Gy}}, \mathrm{~V}_{30 \mathrm{~Gy}}\right)$ were 
the main predictors for SRP and also suggested that with new technologies such as IMRT and hypo-fractionated RT additional studies of corresponding dose-volume parameters should be performed for better guidance in practice. Shaikh et al. (10) studied radiation pneumonitis in patients receiving taxane-based trimodality therapy for locally advanced esophageal cancer. In their study the authors concluded that the volumes covered by $5 \mathrm{~Gy}\left(\mathrm{~V}_{5 \mathrm{~Gy}}\right)$, 10Gy $\left(\mathrm{V}_{10 \mathrm{~Gy}}\right)$, 20Gy $\left(\mathrm{V}_{20 \mathrm{~Gy}}\right)$ and $30 \mathrm{~Gy}\left(\mathrm{~V}_{30 \mathrm{~Gy}}\right)$ were associated with risk of RP grade 2 plus and $\mathrm{V} 5_{\mathrm{Gy}} \leq$ $65 \%$ was the optimal threshold to prevent it. Other studies have also supported that the low dose volume of lung was associated with an increase in risk of RP $(11,12)$.

In the 1930's, the heart was considered as a radio-resistant organ below a dose of 30Gy (13), but current studies have shown that the cardiovascular disease could occur with mean doses as low as 3 to $17 \mathrm{~Gy}$ (14). However, at low doses the typical latent period for cardiac related problems is often long. The risk of myocardial infarction after post lumpectomy radiation treatment for left sided breast cancer (15) is more than right sided breast cancer and it has also been found that increase in radiation dose to heart leads to increased cardiac related mortality $(16,17)$. Darby et al. (18) reported that 1 Gy added to the mean heart dose could increase the rate of ischemic heart disease by $7.4 \%$, regardless of the threshold dose. Also, there is a relationship reported between low-radiation doses ( $\sim 5$ Gy) and cardiac mortality (19). Data published by authors such as Hortobagyi et al. (20) on anthracycline and trastuzumab in Ca-breast showed that patients who had received anthracycline based chemotherapy were at a higher risk for developing cardiac toxicity.

In long-term survivors, second malignancy is also a cause of non-breast cancer mortality. Stovall et al. (21) found that women who were less than 40 years of age and received a radiation dose more than $10 \mathrm{~Gy}$ to the contralateral breast had a 2.5 times higher long-term risk of developing a second primary in contralateral breast.

Radiotherapy planning of the breast cancer has challenges in balancing delivery of adequate radiation dose to the breast and internal mammary chain (IMC) nodes with sparing of heart, lungs and contra lateral breast mainly due to large tissue in-homogeneity (22). There are several guidelines available for breast contouring like Radiotherapy Oncology Group (23) (RTOG), European Society for Radiotherapy and Oncology (24) (ESTRO) and Project on Cancer of the Breast (25) (PROCAB) guidelines. The planning target volume (PTV) with RTOG-1005 guidelines for intact breast or post modified radical mastectomy (MRM) chest wall is very irregular and with conventional 3 dimensional (3D) planning, it is not possible to conform the dose distribution to this shape. The Tangential Field in Field (TFIF) technique is often not able to achieve the desired coverage of the PTV, and ipsilateral lung and heart dose volume constraints are also violated. But Intensity Modulated Radiotherapy (IMRT) and Volumetric Modulated Arc Therapy (VMAT) planning techniques are able to conform the dose to concave/irregularly shaped PTV's in the breast or chest wall with lower dose to ipsilateral lung and heart. In IMRT planning, generally an odd number of fields and inverse optimization are used to improve the dose homogeneity, conformity and avoidance of normal tissues such as heart and lung (26) and contra-lateral breast. The VMAT is a novel form of IMRT, in which generally partial arc fields are used to improve dose homogeneity and conformity in the PTV, reduce dose to normal tissues, and also reduce Monitor Units (MU's)
In breast cancer radiation planning, VMAT results in an increased low dose radiation spillage to lung, heart and contralateral breast as compared to conventional plans (27). TFIF plans on the other hand have shown to reduce the number of MUs and treatment time but with inferior PTV coverage as compared to VMAT. Also, lung volume receiving 20 Gy or above is slightly higher in TFIF as compared to VMAT.

In this retrospective study we have attempted composite treatment planning to reduce the dose to heart, both the lungs, and opposite breast in radiotherapy to left breast or left chest wall without compromising on dose homogeneity and conformity of the PTV. As a result, we expect a decrease in the incidences of long term complications and radiation induced secondary malignancies with the composite treatment technique.

\section{Materials and Methods}

\section{Patients}

A total of 30 patients with left Ca-breast were selected for this retrospective study having equal number of patients in two groups namely post breast conserving surgery (BCS) and post modified radical mastectomy (MRM). The planning computed tomography (CT) data were taken in the head first supine position with $5 \mathrm{~mm}$ thick contiguous slices from the level of mandible to $3 \mathrm{~cm}$ inferior to the last rib with the CT simulator (Somtom Definition AS20 Siemens, Munich, Germany).

\section{Target delineation}

The Clinical Target Volume (CTV) for breast or chest wall and supraclavicular nodes were delineated according to RTOG (23) (1005) guideline. The PTV was cropped $5 \mathrm{~mm}$ and $3 \mathrm{~mm}$ in the body contoured for BCS and MRM groups, respectively. The organs at risk (OARs) such as ipsilateral lung, contra-lateral lung, heart, opposite breast, esophagus, left anterior descending artery (LAD) and spinal cord were contoured (Figure 1). The PTVs and OARs were contoured by the same oncologist for all the patients.

\section{Treatment planning}

All treatment plans were generated on Eclipse (Varian Medical System, Palo Alto, California, United States) Treatment Planning System version 10.0 for hypo fractionation of $42.5 \mathrm{~Gy}$ in 16 fractions. The most common site for recurrence is chest wall in breast malignancy (28), so for MRM cases, a combined plan comprising 10 fractions with $5 \mathrm{~mm}$ thick bolus and remaining 6 fractions without bolus was generated. The selection of bolus and no-bolus sub-plans was in such way to increase the skin to $80-85 \%$ of the prescribed dose (29) for treating microscopic disease due to skin violation by malignant cells during surgery. All plans used 6MV photon beam and $2.5 \mathrm{~mm}$ dose calculation grid. For evaluation purposes the boost treatment plan was not included. Our aim was, the $95 \%$ of PTV should be covered with $95 \%$ of the prescribed dose with minimal dose to OARs.

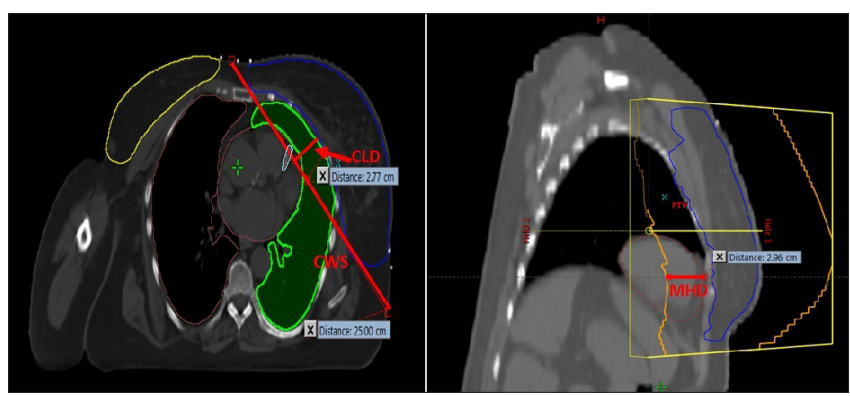

Figure 1. An axial and Sagittal slice showing contour of PTV and OAR's 

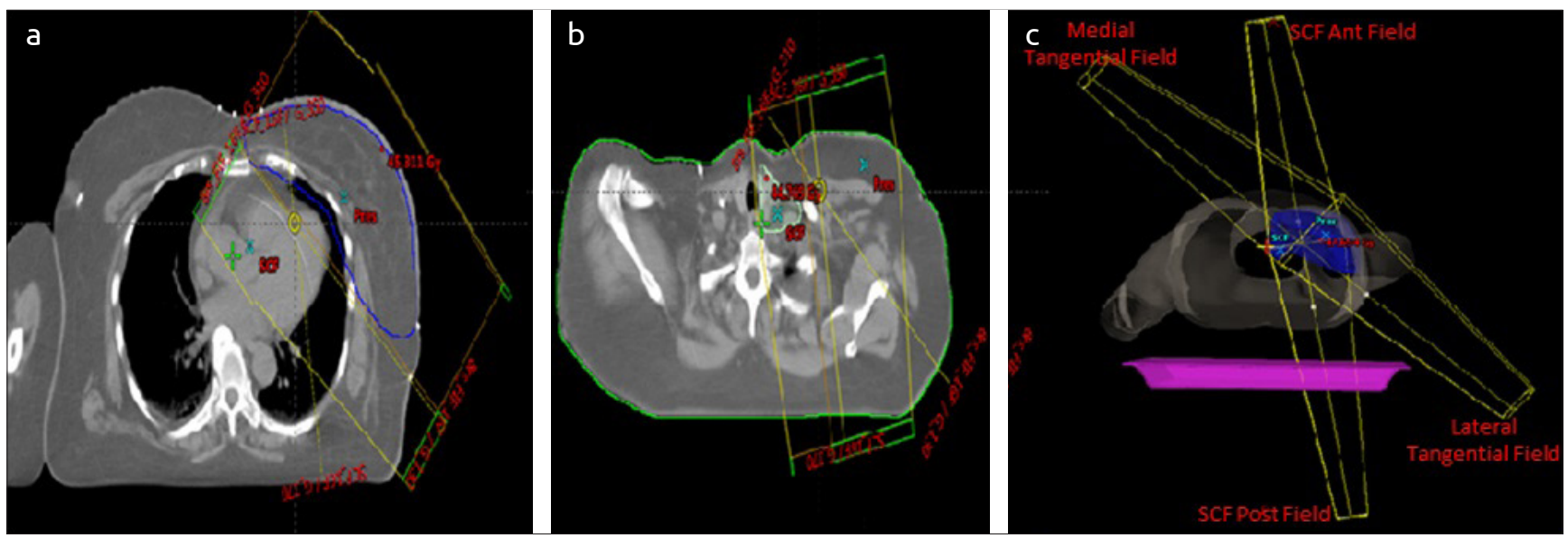

Figure 2. a-c. TFIF planning fields (a) Axial slice with medial and lateral tangential fields (b) Axial slice with anterior and posterior SCF fields (c) Beam's eye view
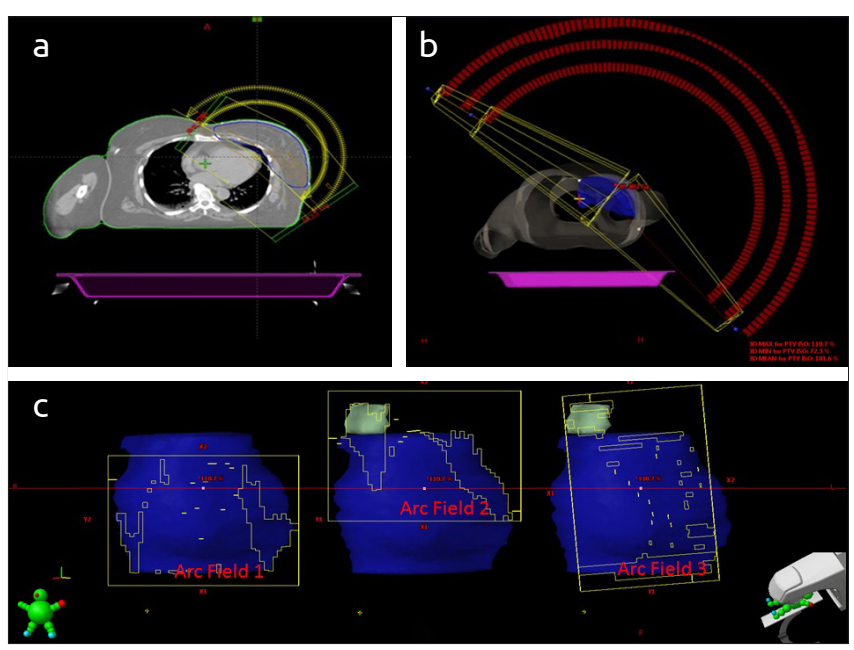

Figure 3. a-c. VMAT planning Fields (a) Axial slice with three partial arc fields (b) Beam's eye view

\section{Detailed treatment planning procedure}

The TFIF plan was the combination of two mono-isocentric plans. In the first plan for the chest wall/breast two main tangential fields namely medial tangential and lateral tangential fields with subfields were placed with gantry angle ranging between $305-315^{\circ}$ and $125-135^{\circ}$, respectively. In the second plan for supraclavicular (SC) nodes, one anterior field was placed with gantry angle ranging between $350-0^{\circ}$ and an additional posterior field was placed as $170-180^{\circ}$ gantry angle, to avoid the high dose to the skin (Figure 2). For calculations, two normalization points were used; one for chest region and the other for SC region. Gantry angles, collimator angles, beam weights and MLC shapes were optimized to get the best plan.

In VMAT technique, 3 partial coplanar arc beams with arc angle ranging between $300-310^{\circ}$ to $135-155^{\circ}$ (Figure 3) were used with a single isocenter in such a way that no direct beam entered through the contralateral lung or breast. The maximum MLC leaf travel distance (distance between the most extended leaf and the most retracted leaf on the same side) for a Varian linear accelerator (Palo Alto, California, U.S.) is 15 $\mathrm{cm}$. If the field width is more than $15 \mathrm{~cm}$ then the plan optimization was compromised due to MLC reach. Therefore, for better optimization the X-Jaw was opened asymmetrically with a collimator angle $90^{\circ}$ to cover the chest wall/ breast PTV and the SC nodes in cranial-caudal direction for two arc fields. The Y-jaw was opened according to PTV width and the remaining arc field was placed with symmetric X-Jaw and a collimator angle between $5-10^{\circ}$ (Figure 3). The plan was optimized with progressive resolution optimizer (PRO). The tissue in-homogeneity correction was considered during optimization and anisotropic analytical algorithm (AAA, version 10.0.28) was used for dose calculation.

The Composite plans were a combination VMAT (8-10 fractions) and TFIF (remaining fractions) to ensure minimal doses to OARs without compromising the coverage of the PTV in such a way that $95 \%$ of the prescribed dose covered at least $95 \%$ of the PTV. Also, not more than $15 \%$ of the volume of PTV exceeded $105 \%$ of the prescribed dose.

\section{Dosimetric evaluation}

Dose Volume Histograms (DVH) were used to evaluate the PTV and the OARs. A combined PTV of breast/ chest wall and SCF nodes was used for the evaluation purposes. The following parameters were used to evaluate the plan quality: dose to $95 \%$ volume of PTV $\left(\mathrm{D}_{95 \%}\right)$, dose to $5 \%$ volume of PTV $\left(\mathrm{D}_{5 \%}\right)$, volume of PTV covered by $95 \%$ of prescribed dose $\left(\mathrm{V}_{95 \%}\right)$, volume of PTV $\left(\mathrm{V}_{\text {PTV }}\right)$, irradiated volume of the body covered with $95 \%$ of prescribed dose $\left(\mathrm{TIV}_{95 \%}\right)$, volume of PTV covered with more than $105 \%$ of the prescribed dose $\left(\mathrm{V}_{105 \%}\right)$, irradiated volume of the body outside the PTV covered with $100 \%$ of the prescribed (hot spot) in $\mathrm{cm}^{3}$, and integral dose in Gy-cm ${ }^{3}$. Additionally, Homogeneity Index (HI), Conformity Index (CI) and Integral Dose (ID) were also estimated. The HI was calculated by the following formula (30).

$\mathrm{HI}=$

$$
D_{5 \%}-D_{95 \%}
$$

$$
D_{\text {Press }}
$$

Where $\mathrm{D}_{\text {pres }}$ is the prescribed dose. The lower HI value meant better homogeneity. The CI was calculated with by following formula (31).

$$
\mathrm{CI}=\frac{V_{95 \%}}{V_{P T V}} \times \frac{V_{95 \%}}{T I V_{95 \%}}
$$

The ideal value of CI is 1 . The ID was estimated to indicate the dose deposited in healthy tissues of body outside the PTV and given by following formula (32).

ID $=$ Total Body Volume $\times D_{m}$ 
Where Dmean PTV out is mean dose deposition in healthy tissues of body outside PTV.

Also, the dosimetric data such as percentage volume covered with 5 Gy (V5Gy), 10 Gy (V10Gy), 20 Gy(V20Gy), mean dose (Dmean) for lung and heart were estimated, and Dmean for LAD and opposite breast were estimated.

\section{Statistical analysis}

All computational statistics were performed with statistical analysis in social science software (SPSS) Statistics package (IBM SPSS Corp.; Armonk, New York, USA), version 24. The Wilcoxon signed rank test was used to analyze the difference in dosimetric parameters and $p$ value $<0.05$ was considered statistically significant.

\section{Table 1. PTV, lung and heart characteristic for BCS and MRM patients ( $n=15$, arithmetic mean and standard deviation)}

\begin{tabular}{|llc}
\hline Parameters & & Mean \pm SD \\
\hline Volume of PTV $(\mathrm{cc})$ & BCS & $1511.03 \pm 450.32$ \\
& MRM & $1037.13 \pm 243.58$ \\
CWS of BCS $(\mathrm{cm})$ & BCS & $25.2 \pm 2.9$ \\
& MRM & $25.01 \pm 2.2$ \\
CLD $(\mathrm{cm})$ & BCS & $2.9 \pm 0.43$ \\
& MRM & $3.16 \pm 0.5$ \\
MHD $(\mathrm{cm})$ & BCS & $2.91 \pm 0.85$ \\
& MRM & $2.73 \pm 0.45$
\end{tabular}

cc: centimeter cube; CWS: Chest Wall Separation; CLD: Central Lung Distance; $\mathrm{MHL}$ : Maximum heart Length.

\section{Results}

The data set was divided into two groups for analyses: Group 1 comprised of patients who had undergone BCS and group 2 comprised of patients who had undergone MRM. The average PTV volumes, chest wall separation (CWS), central lung distance (CLD) and maximum heart distance (MHD) for both the groups are summarized in Table 1. The CLD was defined as the perpendicular distance from the posterior tangential field edge to the posterior part of the anterior chest wall, and the MHD was measured on the CT slice with the thickest section of heart contained within the field defined as the distance between the anterior cardiac contour crossing over the posterior edge of the tangential fields The CWS was defined as the distance between the most posterior field edges of the non- divergent tangential beams measured at the centre of the cranio-caudal axis (33).

The plan selection criteria were: $\mathrm{D}_{95 \%}$ of the PTV should be at least $95 \%$ of the prescription dose (42.5 Gy), and maximum point dose within the PTV should be kept below $110 \%\left(\mathrm{~V}_{110 \%} \sim 0\right)$ of the prescription dose. These criteria were not met with TFIF plans.

\section{Target coverage}

The composite planning technique generated the best results in terms of PTV coverage and dose homogeneity in both the groups. The $\mathrm{D}_{95 \%}$, $\mathrm{V}_{95 \%}, \mathrm{~V}_{105 \%}$, mean CI, HI and ID values are shown in tables Table 2 and 3 for the BCS and MRM groups, respectively. Figure 4 shows the dose distribution for all the techniques.

\section{OAR sparing}

The comparison of the average dosimetric parameters of the OAR is listed in Table 4 and Table 5 for BCS and MRM groups, respectively.

\section{Planning time and monitor units}

The planning time for VMAT was about 3 to 4 hours and higher than TFIF about 1 hour because of beam modeling and inverse planning. The mean values of MU for total treatment (16 fractions) in BCS group were

Table 2. The comparable target Dosimetric parameters for three techniques for BCS group ( $n=15$, arithmetic mean and standard deviation)

\begin{tabular}{|c|c|c|c|c|c|c|}
\hline \multirow[b]{2}{*}{ Parameters } & \multirow[b]{2}{*}{$\begin{array}{c}\text { Composite Plan } \\
\text { Mean } \pm \text { SD }\end{array}$} & \multirow[b]{2}{*}{$\begin{array}{c}\text { VMAT } \\
\text { Mean } \pm S D\end{array}$} & \multirow[b]{2}{*}{$\begin{array}{c}\text { TFIF } \\
\text { Mean } \pm S D\end{array}$} & \multicolumn{3}{|c|}{ Estimated $p$ values } \\
\hline & & & & $\begin{array}{l}\text { TFIF vs } \\
\text { VMAT }\end{array}$ & $\begin{array}{c}\text { TFIF vs } \\
\text { Composite }\end{array}$ & $\begin{array}{c}\text { Composite vs } \\
\text { VMAT }\end{array}$ \\
\hline Hotspot (cc) & $37.36 \pm 24.41$ & $33.43 \pm 19.78$ & $242.45 \pm 117.64$ & $0^{\mathrm{a}}$ & $0^{\mathrm{b}}$ & 0.11 \\
\hline$D_{95 \%}(G y)$ & $40.41 \pm 1.1$ & $40.43 \pm 0.57$ & $38.6 \pm 1.19$ & $0^{\mathrm{a}}$ & $0^{\mathrm{b}}$ & 0.21 \\
\hline $\mathrm{V}_{95 \%}(\%)$ & $94.99 \pm 1.7$ & $95.01 \pm 1.78$ & $92.85 \pm 3.95$ & $0.02^{\mathrm{a}}$ & $0^{\mathrm{b}}$ & 0.45 \\
\hline $\mathrm{V}_{105 \%}(\%)$ & $5.56 \pm 5.05$ & $11.82 \pm 6.39$ & $11.8 \pm 9.6$ & 0.89 & $0^{\mathrm{b}}$ & $\mathrm{Ob}$ \\
\hline$D_{5 \%}(G y)$ & $43.59 \pm 0.41$ & $44.97 \pm 0.43$ & $45.16 \pm 0.73$ & 0.31 & $0^{\mathrm{b}}$ & $\mathrm{ob}$ \\
\hline Dmean (Gy) & $42.95 \pm 0.32$ & $43.24 \pm 0.36$ & $42.58 \pm 0.45$ & $0^{\mathrm{a}}$ & $0^{\mathrm{b}}$ & 0.12 \\
\hline Conformity Index & $0.87 \pm 0.02$ & $0.88 \pm 0.02$ & $0.68 \pm 0.05$ & $0^{\mathrm{a}}$ & $0^{\mathrm{b}}$ & 0.18 \\
\hline Homogeneity Index & $0.074 \pm 0.03$ & $0.11 \pm 0.01$ & $0.15 \pm 0.04$ & $0.01^{\mathrm{a}}$ & $0^{\mathrm{b}}$ & $0.015^{b}$ \\
\hline Integral Dose (Gy.cc) & $\begin{array}{c}100902.45 \pm \\
30757.51\end{array}$ & $\begin{array}{l}118711.9 \pm \\
32284.66\end{array}$ & $\begin{array}{c}82882.62 \pm \\
32648.73\end{array}$ & $0^{c}$ & $0.01^{c}$ & 0 \\
\hline
\end{tabular}

Hotspot: The volume outside of PTV covered by more than prescribed dose (cc); $\mathrm{D}_{95 \%}$ : Dose received by $95 \%$ of the volume (Gy); $\mathrm{V}_{95 \%}$ : volume covered by at least $95 \%$ of the prescribed dose $(\%) ; V_{105 \%}$ : Volume covered by more than $105 \%$ of the prescribed dose (\%); $D_{5 \%}$ : Dose received by $5 \%$ of the volume (Gy); p value ${ }^{a}<0.05$ for VMAT plan; $p$ value ${ }^{b}<0.05$ for Composite plan; $p$ value $e^{c}<0.05$ for TFIF plan 

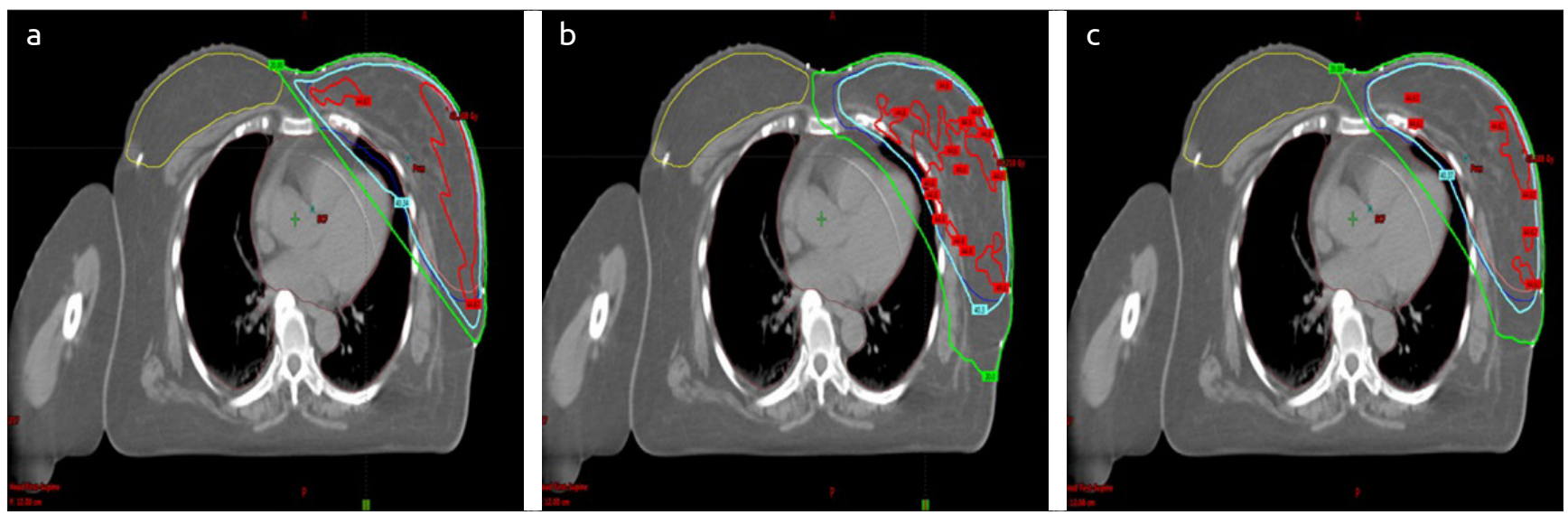

Figure 4. a-c. Dose Distribution axial view red line indicates for $105 \%$, cyan for $95 \%$ and green for $20 \%$ of the prescribed dose for (a) TFIF (b) VMAT (c) Composite Plan

Table 3. The comparable target Dosimetric parameters for three techniques for MRM group ( $n=15$, arithmetic mean and standard deviation)

\begin{tabular}{|c|c|c|c|c|c|c|}
\hline \multirow[b]{2}{*}{ Parameters } & \multirow[b]{2}{*}{$\begin{array}{c}\text { Composite Plan } \\
\text { Mean } \pm S D\end{array}$} & \multirow[b]{2}{*}{ 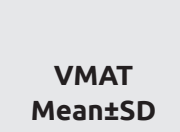 } & \multirow[b]{2}{*}{$\begin{array}{c}\text { TFIF } \\
\text { Mean } \pm S D\end{array}$} & \multicolumn{3}{|c|}{ Estimated $p$ values } \\
\hline & & & & $\begin{array}{l}\text { TFIF vs } \\
\text { VMAT }\end{array}$ & $\begin{array}{l}\text { TFIF vs } \\
\text { Composite }\end{array}$ & $\begin{array}{c}\text { Composite vs } \\
\text { VMAT }\end{array}$ \\
\hline Hotspot (cc) & $51.13 \pm 19.18$ & $46.41 \pm 20.83$ & $311.99 \pm 131.19$ & $0.00^{\mathrm{a}}$ & $0.00^{\mathrm{b}}$ & 0.16 \\
\hline$D_{95 \%}(G y)$ & $40.33 \pm 0.64$ & $40.18 \pm 0.58$ & $38.5 \pm 1.16$ & $0.00^{\mathrm{a}}$ & $0.01^{\mathrm{b}}$ & 0.33 \\
\hline $\mathrm{V}_{95 \%}(\%)$ & $95.37 \pm 1.73$ & $94.57 \pm 1.94$ & $92.99 \pm 2.29$ & $0.02^{\mathrm{a}}$ & $0.00^{\mathrm{b}}$ & 0.13 \\
\hline $\mathrm{V}_{105 \%}(\%)$ & $10.75 \pm 4.22$ & $14.37 \pm 4.41$ & $20.26 \pm 8.9$ & 0.89 & $0.00^{\mathrm{b}}$ & $0.02^{\mathrm{b}}$ \\
\hline$D_{5 \%}(G y)$ & $43.99 \pm 0.23$ & $45.01 \pm 0.56$ & $45.65 \pm 0.9$ & 0.31 & $0.00^{\mathrm{b}}$ & $0.034^{b}$ \\
\hline Dmean (Gy) & $43.23 \pm 0.2$ & $43.37 \pm 0.2$ & $43.09 \pm 0.44$ & $0.00^{\mathrm{a}}$ & 0.15 & $0.01^{b}$ \\
\hline Conformity Index & $0.82 \pm 0.06$ & $0.78 \pm 0.2$ & $0.58 \pm 0.07$ & $0.00^{\mathrm{a}}$ & $0.00^{\mathrm{b}}$ & 0.09 \\
\hline Homogeneity Index & $0.086 \pm 0.02$ & $0.11 \pm 0.02$ & $0.17 \pm 0.03$ & $0.01^{\mathrm{a}}$ & $0.00^{\mathrm{b}}$ & $0.035^{b}$ \\
\hline Integral Dose (Gy.cc) & $\begin{array}{c}111666.4 \pm \\
23440.47\end{array}$ & $\begin{array}{c}125945.68 \pm \\
23180.06\end{array}$ & $\begin{array}{c}83526.36 \pm \\
17842.6\end{array}$ & $0.00^{c}$ & $0.00^{c}$ & $0.01^{b}$ \\
\hline
\end{tabular}

7720, 13519, 11344 and in MRM group were 10582, 15122 and 13420 for TFIF, VMAT and composite planning techniques respectively.

\section{Discussion and Conclusion}

Many studies have shown that in BCS or in MRM cases the VMAT planning technique gave better target coverage and lower doses to OARs as compared to 3-dimensional conformal radiotherapy (3DCRT) or conventional IMRT (, ). Viren et al. () showed that there was no significant difference in OAR doses between 3CDRT and tangent IMRT (t-IMRT), although in t-IMRT, the MU's were higher. In this study, the authors compared these planning techniques to VMAT. They concluded that using FIF technique, the planning and treatment time could be reduced.

Al-Rahbi et al. (37) reported that the forward plan IMRT technique (FP-IMRT) was a simple and efficient planning technique in breast cancer treatment. In their study, 20 left side breast cancer patients were included. The homogeneity and conformity indices were similar for inverse IMRT (IP-IMRT), FP-IMRT and 3D-CRT techniques. The V5Gy for heart in IP-IMRT technique was $72.9 \%$, whereas in our composite technique, it was $38.35 \%$ and $35.1 \%$ for BCS and MRM group respectively. Zhang et al. (38) reported that the VMAT technique was better than the IMRT to achieve target coverage and normal organ sparing. In their study, the V5Gy for ipsilateral lung and heart were $61 \%, 77 \%$ for IMRT and 66\%, 78\% for VMAT respectively. The contra- lateral lung and breast mean doses were lower in VMAT (4.49 Gy and 1.7 Gy) than IMRT (4.67 Gy and 2.3 Gy). In our composite technique V5Gy for ipsilateral lung value was $57.62 \%$ and $62.49 \%$ for BCS and MRM group respectively. The V5Gy for heart was $38.35 \%$ and $35.1 \%$ for BCS and MRM group respectively. The contra-lateral lung and opposite breast mean dose were also lower in our composite technique than the above quoted study.

A similar study was done by Shaffer et al. (39) In this study VMAT technique improved the plan quality and achieved better normal organ 
Table 4. The comparable OAR's Dosimetric parameters for three techniques for BCS group ( $n=15$, arithmetic mean and standard deviation)

\begin{tabular}{|c|c|c|c|c|c|c|}
\hline \multirow[b]{2}{*}{ Parameters } & \multirow[b]{2}{*}{$\begin{array}{c}\text { Composite Plan } \\
\text { Mean } \pm S D\end{array}$} & \multirow[b]{2}{*}{ 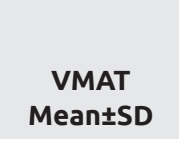 } & \multirow[b]{2}{*}{$\begin{array}{c}\text { TFIF } \\
\text { Mean } \pm S D\end{array}$} & \multicolumn{3}{|c|}{ Estimated $p$ values } \\
\hline & & & & $\begin{array}{l}\text { TFIF vs } \\
\text { VMAT }\end{array}$ & $\begin{array}{c}\text { TFIF vs } \\
\text { Composite }\end{array}$ & $\begin{array}{c}\text { Composite vs } \\
\text { VMAT }\end{array}$ \\
\hline Heart $V_{5 G y}(\%)$ & $38.35 \pm 10.63$ & $73.71 \pm 89.99$ & $21.44 \pm 6.12$ & $0^{c}$ & $0^{c}$ & $0^{\mathrm{b}}$ \\
\hline Heart $\mathrm{V}_{10 \mathrm{CG}}(\%)$ & $18.43 \pm 5.88$ & $24.93 \pm 6.59$ & $14.53 \pm 4.67$ & $0^{c}$ & $0^{c}$ & $0^{\mathrm{b}}$ \\
\hline Heart $\mathrm{V}_{20 \mathrm{y} y}(\%)$ & $8.17 \pm 3.23$ & $8.02 \pm 2.47$ & $11.63 \pm 4.65$ & $0^{\mathrm{a}}$ & $0.01^{b}$ & 0.25 \\
\hline Heart $D_{\text {mean }}(G y)$ & $6.3 \pm 1.42$ & $7.97 \pm 1.25$ & $6.03 \pm 1.35$ & 0.23 & $0^{c}$ & $0^{\mathrm{b}}$ \\
\hline LAD Dmean (Gy) & $11.22 \pm 6.53$ & $13.37 \pm 4.86$ & $20.31 \pm 9.41$ & $0.02^{\mathrm{a}}$ & $0.01^{\mathrm{b}}$ & 0.23 \\
\hline Ipsilateral Lung $\mathrm{V}_{56 \mathrm{y}}(\%)$ & $57.62 \pm 10.98$ & $68.59 \pm 10.73$ & $43.3 \pm 11.69$ & $0^{c}$ & 0.23 & $0^{\mathrm{b}}$ \\
\hline Ipsilateral Lung $\mathrm{V}_{10 \mathrm{cy}}(\%)$ & $37.88 \pm 9.82$ & $43.89 \pm 8.17$ & $32.19 \pm 10.03$ & $0^{c}$ & $0^{c}$ & $0^{\mathrm{b}}$ \\
\hline Ipsilateral Lung $\mathrm{V}_{20 \mathrm{~Gy}}(\%)$ & $25.23 \pm 7.6$ & $23.65 \pm 5.68$ & $26.42 \pm 9.03$ & $0.05^{\mathrm{a}}$ & $0.04^{\mathrm{b}}$ & 0.07 \\
\hline Ipsilateral Lung $D_{\text {mean }}$ (Gy) & $10.3 \pm 2.28$ & $12.85 \pm 2.34$ & $13.28 \pm 2.31$ & 0.12 & 0.16 & 0.07 \\
\hline Contralateral Lung $\mathrm{V}_{5 \mathrm{GC}}(\%)$ & $6.03 \pm 6.66$ & $15.58 \pm 10.38$ & $0.01 \pm 0.04$ & $0^{c}$ & $0^{c}$ & $0^{\mathrm{b}}$ \\
\hline Contralateral Lung $\mathrm{V}_{10 \mathrm{~Gy}}(\%)$ & $0.18 \pm 0.38$ & $2.37 \pm 2.85$ & $0 \pm 0$ & $0^{c}$ & 0.07 & $0^{\mathrm{b}}$ \\
\hline Contralateral Lung $D_{\text {mean }}(G y)$ & $1.93 \pm 0.71$ & $3.08 \pm 0.85$ & $0.38 \pm 0.21$ & $0^{c}$ & $0^{c}$ & $0^{\mathrm{b}}$ \\
\hline Total Lung $\mathrm{V}_{5 \mathrm{CG}}(\%)$ & $28.71 \pm 8.42$ & $39.64 \pm 9.22$ & $19.67 \pm 5.46$ & $0^{c}$ & $0^{c}$ & $0^{\mathrm{b}}$ \\
\hline Total Lung $\mathrm{V}_{10 \mathrm{~Gy}}(\%)$ & $17.35 \pm 4.69$ & $21.28 \pm 4.79$ & $14.59 \pm 4.58$ & $0^{c}$ & $0^{c}$ & $0^{\mathrm{b}}$ \\
\hline Total Lung $\mathrm{V}_{20 \mathrm{~Gy}}(\%)$ & $10.84 \pm 5.5$ & $10.75 \pm 2.68$ & $11.99 \pm 4.15$ & 0.06 & 0.21 & 0.26 \\
\hline Total Lung $D_{\text {mean }}(G y)$ & $6.8 \pm 1.55$ & $7.67 \pm 1.33$ & $5.75 \pm 1.67$ & $0^{c}$ & $0^{c}$ & $0^{\mathrm{b}}$ \\
\hline Opposite Breast $D_{\text {mean }}(G y)$ & $2.55 \pm 2.92$ & $2.83 \pm 0.49$ & $0.38 \pm 0.42$ & $0^{c}$ & $0^{c}$ & $0.01^{b}$ \\
\hline
\end{tabular}

sparing than the conventional IMRT (c-IMRT) and 3D-CRT techniques. Also, the V5Gy of heart and lung were $83 \%$ and $70.1 \%$ for VMAT and $100 \%$ and $91.9 \%$ for c-IMRT, respectively. Berrington de Gonzalez et al. (40) published a study on dose to the contra-lateral breast and risk of second primary breast cancer and showed that the risk was dose dependent and inversely related to age. Women under 40 years of age had an elevated risk of second breast cancer. Based on this study, younger patients should benefit from a technique in which lesser dose to contra-lateral breast is achieved. Yorke et al. (41) showed the effect of low doses (less than 20Gy) on the development of RP. A complication rate of $20 \%$ was expected if more than $50 \%$ of the lung volume received $10 \mathrm{~Gy}$ thus highlighting the need to minimize the dose to heart and lung.

Our results show that the HI and CI indices for TFIF were poorer than the other two techniques and also did not achieve the acceptable criteria. Further, high dose volumes such as $\mathrm{V}_{20 \mathrm{~Gy}}$ for lungs and heart were also higher for TFIF. The low dose exposure with VMAT was significantly higher that could translate into increased probability of radiation-induced carcinomas (42).

The V105\% is significantly correlated with higher probability of developing skin toxicity (43). The $\mathrm{V}_{105 \%}$ of the whole breast PTV should be less than $10 \%$ to keep grade 3 dermatitis rates below $2 \%$. In our study nique and significantly lower than both VMAT $(11.82 \%, \mathrm{p}=0.001)$ and TFIF (11.8\%, $\mathrm{p}=0.0006)$ for BCS and for MRM groups, it was $10.75 \%$ in composite plan and statistically lower than VMAT as $14.37 \%(\mathrm{p}=0.003)$ and TFIF as $20.26 \%(\mathrm{p}=0.023)$.

In our study, the composite plan showed significantly better results for low dose volume irradiation as compared to VMAT plans for both the groups of patients. The ipsilateral lung dose $\mathrm{V}_{5 \mathrm{~Gy}}$ in the composite plan was reduced by $15.99 \%$ and $8.42 \%$ of VMAT for BCS and MRM groups, respectively without compromising the homogeneity and conformity indices. The ipsilateral lung $\mathrm{V}_{10 \mathrm{~Gy}}$ of was also reduced by $13.69 \%$ and $3.03 \%$ of VMAT for BCS and MRM group, respectively. The contra-lateral lung $\mathrm{V}_{5 \mathrm{~Gy}}$ and $\mathrm{V}_{10 \mathrm{~Gy}}$ values in the composite plan were significantly reduced by $61.29 \%$ and $92.4 \%$ of VMAT for BCS and $50.14 \%$ and $38.02 \%$ for MRM groups. The mean dose of contra-lateral lung was also reduced by $37.33 \%$ and $33.53 \%$ of VMAT value in the composite plan for BCS and MRM groups, respectively.

Similarly, the $\mathrm{V}_{5 \mathrm{~Gy}}$ of heart was significantly reduced in the composite plan by $47.97 \%$ and $21.22 \%$ of the VMAT values for BCS and MRM groups, respectively. The $\mathrm{V}_{10 \mathrm{~Gy}}$ of heart was also reduced by $26.07 \%$ and $45.67 \%$ of VMAT values for BCS and MRM groups in the composite planning technique. The mean dose to heart in the composite plan was reduced by $20.95 \%$ and $18.52 \%$ of VMAT value for the BCS and MRM groups, respectively. The contra-lateral breast mean doses 
Table 5. The comparable OAR's Dosimetric parameters for three techniques for MRM group ( $n=15$, arithmetic mean and standard deviation)

\begin{tabular}{|c|c|c|c|c|c|c|}
\hline \multirow[b]{2}{*}{ Parameters } & \multirow[b]{2}{*}{$\begin{array}{c}\text { Composite Plan } \\
\text { Mean } \pm S D\end{array}$} & \multirow[b]{2}{*}{ 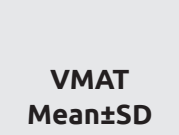 } & \multirow[b]{2}{*}{$\begin{array}{c}\text { TFIF } \\
\text { Mean } \pm S D\end{array}$} & \multicolumn{3}{|c|}{ Estimated $p$ values } \\
\hline & & & & $\begin{array}{l}\text { TFIF vs } \\
\text { VMAT }\end{array}$ & $\begin{array}{c}\text { TFIF vs } \\
\text { Composite }\end{array}$ & $\begin{array}{c}\text { Composite vs } \\
\text { VMAT }\end{array}$ \\
\hline Heart $\mathrm{V}_{5 \mathrm{~Gy}}(\%)$ & $35.1 \pm 8.81$ & $44.56 \pm 11.09$ & $20.55 \pm 5.95$ & $0.00^{c}$ & $0.00^{c}$ & $0.00^{\mathrm{b}}$ \\
\hline Heart $V_{10 G y}(\%)$ & $18.09 \pm 5.37$ & $33.3 \pm 43.27$ & $15.25 \pm 5.14$ & $0.00^{c}$ & $0.00^{c}$ & $0.00^{\mathrm{b}}$ \\
\hline Heart $V_{20 G y}(\%)$ & $8.71 \pm 3.49$ & $8.53 \pm 2.73$ & $11.93 \pm 4.1$ & $0.00^{\mathrm{a}}$ & $0.00^{b}$ & 0.09 \\
\hline Heart $D_{\text {mean }}(G y)$ & $6.29 \pm 0.97$ & $7.72 \pm 1.25$ & $6.33 \pm 1.56$ & 0.42 & $0.00^{c}$ & $0.00^{\mathrm{b}}$ \\
\hline LAD D $D_{\text {mean }}(G y)$ & $11.45 \pm 6.13$ & $12.87 \pm 4.22$ & $16.09 \pm 9.01$ & $0.02^{\mathrm{a}}$ & $0.02^{b}$ & 0.17 \\
\hline Ipsilateral Lung $\mathrm{V}_{5 \mathrm{G} y}(\%)$ & $62.49 \pm 6.01$ & $68.24 \pm 7.65$ & $50.73 \pm 8.97$ & $0.00^{c}$ & $0.00^{c}$ & $0.00^{\mathrm{b}}$ \\
\hline Ipsilateral Lung $\mathrm{V}_{100 \mathrm{y}}(\%)$ & $44.14 \pm 4.72$ & $45.52 \pm 5.11$ & $39.19 \pm 8.05$ & $0.00^{c}$ & $0.00^{c}$ & 0.28 \\
\hline Ipsilateral Lung $\mathrm{V}_{20 \mathrm{y}}(\%)$ & $28.29 \pm 4.96$ & $27.65 \pm 2.72$ & $32.51 \pm 7.2$ & $0.05^{\mathrm{a}}$ & $0.02^{b}$ & 0.11 \\
\hline Ipsilateral Lung $D_{\text {mean }}(G y)$ & $12.83 \pm 1.5$ & $12.63 \pm 0.98$ & $14.87 \pm 7.16$ & 0.12 & 0.25 & 0.41 \\
\hline Contralateral Lung $\mathrm{V}_{5 \mathrm{~Gy}}(\%)$ & $8.53 \pm 4.01$ & $17.11 \pm 5.97$ & $0.18 \pm 0.7$ & $0.00^{c}$ & $0.00^{c}$ & $0.01^{b}$ \\
\hline Contralateral Lung $\mathrm{V}_{10 \mathrm{y} y}(\%)$ & $0.19 \pm 0.33$ & $3.05 \pm 1.95$ & $0.11 \pm 0.44$ & $0.00^{c}$ & 0.33 & $0.00^{\mathrm{b}}$ \\
\hline Contralateral Lung $\mathrm{D}_{\text {mean }}(\mathrm{Gy})$ & $2.16 \pm 0.39$ & $3.25 \pm 0.54$ & $0.48 \pm 0.17$ & $0.00^{c}$ & $0.00^{c}$ & $0.00^{\mathrm{b}}$ \\
\hline Total Lung $\mathrm{V}_{5 G \mathrm{y}}(\%)$ & $32.92 \pm 4.41$ & $41.27 \pm 5.61$ & $23.45 \pm 5.18$ & $0.00^{c}$ & $0.00^{c}$ & $0.00^{\mathrm{b}}$ \\
\hline Total Lung $\mathrm{V}_{10 \mathrm{y} y}(\%)$ & $20.47 \pm 2.86$ & $22.55 \pm 2.73$ & $18.17 \pm 4.45$ & $0.00^{c}$ & $0.00^{c}$ & $0.02^{\mathrm{b}}$ \\
\hline Total Lung $\mathrm{V}_{20 G y}(\%)$ & $12.96 \pm 2.55$ & $12.63 \pm 1.44$ & $15.09 \pm 3.73$ & 0.06 & $0.01^{b}$ & 0.2 \\
\hline Total Lung $D_{\text {mean }}(G y)$ & $7.87 \pm 0.89$ & $8.38 \pm 0.66$ & $7.29 \pm 1.33$ & $0.00^{c}$ & $0.02^{c}$ & $0.00^{\mathrm{b}}$ \\
\hline Opposite Breast $D_{\text {mean }}(G y)$ & $2.13 \pm 0.6$ & $3.16 \pm 0.62$ & $0.54 \pm 0.58$ & $0.00^{c}$ & $0.00^{c}$ & $0.00^{\mathrm{b}}$ \\
\hline
\end{tabular}

were also significantly reduced by $9.89 \%$ and $32.90 \%$ of the VMAT values in the composite plans for BCS and MRM group, respectively.

Although in this study, the mean heart, LAD and ipsilateral lung dose were higher because the most of the selected patients were with locally advanced disease and RTOG guideline was followed for contouring being liberal than other guidelines like ESTRO, it leads to more MHD, CLD resulting high lung and heart dose. In that scenario we tried to reduce OAR's dose using composite planning technique. There is a scope to treat such patients with deep inspiration breath hold (DIBH) technique, which has advantage to reduce mean heart dose (44) and lung dose (45). But additional cost and challenges to patient as well as staff are also associated with this technique. In our department we have recently started DIBH technique, but the data size is small to analyze.

In the present study, the dosimetric endpoints were compared for three planning techniques in the setting of intact breast and post MRM irradiations. During this study, it was felt that the TFIF technique is easy in planning, required lesser planning time than VMAT and lesser monitor unit to delivered desired dose, but at the same time homogeneity and conformity are poorer than other techniques. The composite plan consisting of a combination of VMAT and TFIF plans resulted in lower doses to the OARs as compared to the VMAT plan, and also in better dose uniformity in the target as compared to the TFIF plan. Thus the composite plan is superior to both the VMAT and TFIF plans alone.
Ethics Committee Approval: N/A.

Informed Consent: N/A.

Peer-review: Externally peer-reviewed.

Author Contributions: Concept - N.K., M.S.H.; Design - N.K.; Supervision - A.K.S., A.K.B., R.K.M., C.G., A.K.A.; Resources - N.K., S.K.; Materials N.K.; Data Collection and/or Processing - N.K.; Analysis and/or Interpretation - N.K., M.K.S.; Literature Search - N.K., M.S.H., S.K., D.K.M.; Writing Manuscript - N.K., M.S.H., Critical Review - N.K., M.K.S., D.K.M.

Conflict of Interest: The authors have no conflicts of interest to declare.

Financial Disclosure: The authors declared that this study has received no financial support.

\section{References}

1. Breast cancer statistics. Retrieved from https://www.wcrf.org/dietandcancer/cancer trends/breast cancer-statistics.

2. El Saghir NS, Khalil MK, Eid T, El Kinge AR, Charafeddine M, Geara F, et al. Trends in epidemiology and management of breast cancer in developing Arab countries: A literature and registry analysis. Int J Surg 2007; 5: 225-233. (PMID: 17660128). [CrossRef]

3. Darby S, McGale P, Correa C, Taylor C, Arriagada R, Clarke M, et al. Effect of radiotherapy after breast-conserving surgery on 10-year recurrence and 15-year breast cancer death: Meta-analysis of individual patient 
data for 10801 women in 17 randomised trials. Lancet 2011; 378: 17071716. (PMID: 22019144). [CrossRef]

4. Clarke M, Collins R, Darby S, Davies C, Elphinstone P, Evans V, et al. Effects of radiotherapy and of differences in the extent of surgery for early breast cancer on local recurrence and 15-year survival: An overview of the randomised trials. Lancet 2005; 366: 2087-2106. (PMID: 16360786). [CrossRef]

5. Lingos TI, Recht A, Vicini F, Abner A, Silver B, Harris JR. Radiation pneumonitis in breast cancer patients treated with conservative surgery and radiation therapy. Int J Radiat Oncol Biol Phys 1991; 21: 355-360. (PMID: 2061112). [CrossRef]

6. Oie Y, Saito Y, Kato M, Ito F, Hattori H, Toyama H, et al. Relationship between radiation pneumonitis and organizing pneumonia after radiotherapy for breast cancer. Radiat Oncol 2013; 8: 56. (PMID: 23497657). [CrossRef]

7. Lind PA, Marks LB, Hardenbergh PH, Clough R, Fan M, Hollis D, et al. Technical factors associated with radiation pneumonitis after local \pm regional radiation therapy for breast cancer. Int J Radiat Oncol Biol Phys 2002; 52: 137-143. (PMID: 11777631). [CrossRef]

8. Gokula K, Earnest A, Wong LC. Meta-analysis of incidence of early lung toxicity in 3-dimensional conformal irradiation of breast carcinomas. Radiat Oncol 2013; 8: 268. (PMID: 24229418). [CrossRef]

9. Wen G, Tan YT, Lan XW, He ZC, Huang JH, Shi JT, et al. New Clinical Features and Dosimetric Predictor Identification for Symptomatic Radiation Pneumonitis after Tangential Irradiation in Breast Cancer Patients. J Cancer 2017; 8: 3795-3802. (PMID: 29151967). [CrossRef]

10. Shaikh T, Churilla TM, Monpara P, Scott WJ, Cohen SJ, Meyer JE, et al. Risk of radiation pneumonitis in patients receiving taxane-based trimodality therapy for locally advanced esophageal cancer. Pract Radiat Oncol 2016; 6: 388-394. (PMID: 27025161). [CrossRef]

11. Komaki R, Liao Z, Liu H, Tucker S, Rice D. Fatal pneumonitis associated with intensity-modulated radiation therapy for mesothelioma: in regard to Allen et al. (Int J Radiat Oncol Biol Phys 2006;65:640-645). Int J Radiat Oncol Biol Phys 2006; 66: 1595-1596. (PMID: 17126220). [CrossRef]

12. Dang J, Li G, Ma L, Diao R, Zang S, Han C, et al. Predictors of grade $\geq$ 2 and grade $\geq 3$ radiation pneumonitis in patients with locally advanced non-small cell lung cancer treated with three-dimensional conformal radiotherapy. Acta Oncologica 2013; 52: 1175-1180. (PMID: 23198719). [CrossRef]

13. Darby SC, Cutter DJ, Boerma M, Constine LS, Fajardo LF, Kodama K, et al. Radiation-Related Heart Disease: Current Knowledge and Future Prospects. Int J Radiat Oncol Biol Phys 2010; 76: 656-665. (PMID: 20159360). [CrossRef]

14. Giordano SH, Kuo YF, Freeman JL, Buchholz TA, Hortobagyi GN, Goodwin JS. Risk of Cardiac Death After Adjuvant Radiotherapy for Breast Cancer. J Natl Cancer Inst 2005; 97: 419-424. (PMID: 15770005). [CrossRef]

15. Paszat LF, Mackillop WJ, Groome PA, Schulze K, Holowaty E. Mortality from myocardial infarction following postlumpectomy radiotherapy for breast cancer: A population-based study in Ontario, Canada. Int J Radiat Oncol Biol Phys 1999; 43: 755-762. ( PMID: 10098430). [CrossRef]

16. Prosnitz RG, Yu X, Zhou S, Kahn D, Hollis DR, Hardenbergh PH, et al. Impact of patient-specific factors in the development of radiation (RT)associated cardiac perfusion defects. J Clin Oncol 2006; 22(14_suppl), 673-673. [CrossRef]

17. Jagsi R, Griffith KA, Koelling T, Roberts R, Pierce LJ. Rates of myocardial infarction and coronary artery disease and risk factors in patients treated with radiation therapy for early-stage breast cancer. Cancer 2007; 109: 650-657. (PMID: 17238178). [CrossRef]

18. Darby SC, Ewertz M, McGale P, Bennet AM, Blom-Goldman U, Brønnum $\mathrm{D}$, et al. Risk of ischemic heart disease in women after radiotherapy for breast cancer. N Engl J Med 2013; 368: 987-998. (PMID: 23484825). [CrossRef]

19. Chung E, Corbett JR, Moran JM, Griffith KA, Marsh RB, Feng M, et al. Is there a dose-response relationship for heart disease with low-dose radiation therapy? Int J Radiat Oncol Biol Phys 2013; 85: 959-964. (PMID:
20. Hortobagyi GN. Trastuzumab in the Treatment of Breast Cancer. N Engl J Med 2005; 353: 1734-1736. (PMID: 16236745). [CrossRef]

21. Stovall M, Smith SA, Langholz BM, Boice JD Jr, Shore RE, Andersson $\mathrm{M}$, et al. Dose to the Contralateral Breast From Radiotherapy and Risk of Second Primary Breast Cancer in the WECARE Study. Int J Radiat Oncol Biol Phys 2008; 72: 1021-1030. (PMID: 18556141). [CrossRef]

22. Fogliata A, Nicolini G, Alber M, Asell M, Dobler B, El-Haddad M, et al. IMRT for breast. A planning study. Radiother Oncol 2005; 76: 300-310. (PMID: 16153730). [CrossRef]

23. Radiation Therapy Oncology Group (RTOG). Breast Cancer Online 2006; 9: 411-418. [CrossRef]

24. Offersen BV, Boersma LJ, Kirkove C. ESTRO consensus guideline on target volume delineation for elective radiation therapy of early stage breast cancer, version 1.1. Radiother Oncol 2016; 118: 205-208. (PMID: 26791404). [CrossRef]

25. Offersen BV, Boersma LJ, Kirkove C, Hol S, Aznar MC, Sola AB, et al. Vessel based delineation guidelines for the elective lymph node regions in breast cancer radiation therapy - PROCAB guidelines. Radiother Oncol 2015; 118: 209-210. (PMID: 26743831). [CrossRef]

26. Fournier-Bidoz, N, Kirova Y, Campana F. Technique alternatives for breast radiation oncology: Conventional radiation therapy to tomotherapy. J Med Phys 2009; 34: 149. (PMID: 20098562). [CrossRef]

27. Muralidhar KR, Soubhagya B, Ahmed S. Intensity modulated radiotherapy versus volumetric modulated arc therapy in breast cancer: A comparative dosimetric analysis. Int J Cancer Ther Oncol 2015; 3: 3210. [CrossRef]

28. Taylor ME, Perez CA, Mortimer JE, Levitt SH, Ieumwananonthachai N, Wahab SH. Breast: Locally advanced (T3 and T4) and recurrent tumors. In perez CA, Brady LW, Halperin EC, Schmidth Ullrich RK, editors. Principles and practices of Radiation Oncology. 4th ed. Philadelphia Lippincott Williams and Wilkins; 2004 p. 1502-53.

29. Remick J, Amin NP. Postmastectomy Breast Cancer Radiation Therapy. Stat Pearls, StatPearls Publishing, 24 September 2019. (PMID: 30085576).

30. Wu Q, Mohan R, Morris M, Lauve A, Schmidt-Ullrich R. Simultaneous integrated boost intensity-modulated radiotherapy for locally advanced head-and-neck squamous cell carcinomas: Dosimetric results. Int J Radiat Oncol Biol Phys 2003; 56: 573-585. (PMID: 12738335). [CrossRef]

31. Atiq M, Atiq A, Iqbal K, Shamsi Q, Andleeb F, Buzdar SA. Evaluation of dose conformity and coverage of target volume for intensity-modulated radiotherapy of pelvic cancer treatment. Indian J Cancer 2017; 54: 379384. (PMID: 29199727). [CrossRef]

32. Aoyama H, Westerly DC, Mackie TR, Olivera GH, Bentzen SM, Patel $\mathrm{RR}$, et al. Integral radiation dose to normal structures with conformal external beam radiation. Int J Radiat Oncol Biol Phys 2006; 64: 962-967. (PMID: 16458781). [CrossRef]

33. Das I, Andrews J, Cao M, Johnstone PA. Correlation of 2D parameters to lung and heart dose-volume in radiation treatment of breast cancer. Acta Oncol 2013; 52: 178-183. (PMID: 2248629). [CrossRef]

34. Johansen S, Cozzi L, Olsen DR. A planning comparison of dose patterns in organ at risk and predicted risk for radiation induced malignancy in the contralateral breast following radiation therapy of primary breast using conventional, IMRT and Volumetric modulated arc treatment techniques. Acta Oncol 2009; 48: 495-503. (PMID: 19169915). [CrossRef]

35. Qiao L, Xie J, Cheng J, Liang J, Dang N, Zhang G, et al. SU-E-P-51: Dosimetric Comparison to Organs at Risk Sparing Using VolumetricModulated Arc Therapy Versus Intensity-Modulated Radiotherapy in Postoperative Radiotherapy of Left-Sided Breast Cancer. Med Phy 2015; 42: 3238-3238. [CrossRef]

36. Virén T, Heikkilä J, Myllyoja K, Koskela K, Lahtinen T, Seppälä J. Tangential volumetric modulated arc therapy technique for left-sided breast cancer radiotherapy. Radiat Oncol 2015; 10: 79. (PMID: 25888866). [CrossRef]

37. Al-Rahbi ZS, Al Mandhari Z, Ravichandran R, Al-Kindi F, Davis CA, Bhasi $S$ et al. Dosimetric comparison of intensity modulated radiotherapy isocentric field plans and field in field (FIF) forward plans in the treatment of breast cancer. J Med Phy 2013; 38: 22-29. (PMID: 23531607). [CrossRef] 
38. Zhang Q, Yu XL, Hu WG, Chen JY, Wang JZ, Ye JS, et al. Dosimetric comparison for volumetric modulated arc therapy and intensity modulated radiotherapy on the left-sided chest wall and internal mammary nodes irradiation in treating post-mastectomy breast cancer. Radiother Oncol 2015; 49: 91-98. (PMID: 25810708). [CrossRef]

39. Shaffer R, Nichol AM, Vollans E, Fong M, Nakano S, Moiseenko V, et al. A comparison of volumetric modulated arc therapy and conventional intensity-modulated radiotherapy for frontal and temporal high-grade gliomas. Int J Radiat Oncol Biol Phys 2010; 76: 1177-1184. (PMID: 19560880). [CrossRef]

40. Berrington de Gonzalez A, Curtis RE, Gilbert E, Berg CD, Smith SA, Stovall M, et al. Second solid cancers after radiotherapy for breast cancer in SEER cancer registries. Br J Cancer 2010; 102: 220-226. [CrossRef]

41. Yorke ED, Jackson A, Rosenzweig KE, Braban L, Leibel SA, Ling CC. Correlation of dosimetric factors and radiation pneumonitis incidence for non-small-cell lung cancer (NSCLC) patients in a recently completed dose escalation study. Int J Radiat Oncol Biol Phys 2005; 63: 672-682. (PMID: 15939548). [CrossRef]

42. Hall EJ, Wuu CS. Radiation-induced second cancers: The impact of 3DCRT and IMRT. Int J Radiat Oncol Biol Phys 2003; 56: 83-88. (PMID: 12694826). [CrossRef]

43. Patel AK, Ling DC, Richman AH, Champ CE, Huq MS, Heron DE, et al. Hypofractionated Whole-Breast Irradiation in Large-Breasted Women-Is There a Dosimetric Predictor for Acute Skin Toxicities? Int J Radiat Oncol Biol Phys 2019; 103: 71-77. (PMID: 30145393). [CrossRef]

44. Hong JC, Rahimy E, Gross CP, Shafman T, Hu X, Yu JB, et al. Radiation dose and cardiac risk in breast cancer treatment: An analysis of modern radiation therapy including community settings. Pract Radiat Oncol 2018; 8: e79-e86. (PMID: 28888675). [CrossRef]

45. Josipovic M, Aznar M, Rydhög J, Thomsen J, Damkjaer S, Nygård L, et al. Locally Advanced Lung Cancer Radiotherapy in Deep Inspiration Breath Hold: Dosimetric Benefits from a Prospective Trial. J Thorac Oncol 2018; 13: S372-S373. [CrossRef] 